\title{
İleri Yaş İnfertil Kadınlarda KOS/IUI Ile IVF Tedavilerinin Sonuçlarının Karşılaştırılması
}

\author{
Comparison of Outcomes of KOH/IUI and IVF Treatment in Advanced Age Infertile Women
}

\section{Selçuk Selçuk ${ }^{1}$, Evrim Bostancı ${ }^{1}$, Mehmet Küçükbaş ${ }^{1}$, Bülent Emre Bilgiç ${ }^{2}$ Hüseyin Tayfun Kutlu ${ }^{1}$, Belgin Devranoglu ${ }^{1}$, Semra Kayataş Eser ${ }^{3}$}

1. Zeynep Kamil EAH, Jinekoloji Bölümü, İstanbul, Türkiye

2. Zeynep Kamil EAH, Embryoloji Bölümü, Istanbul, Türkiye

3. Zeynep Kamil EAH, Jinekoloji Bölümü, İstanbul, Türkiye

\section{$\ddot{O Z Z T}$}

Amaç: Çalışmada 38 yaş üzeri infertil kadınlarda KOS/ IUI ile IVF tedavilerinin sonuçlarının karşılaștırılması amaçlanmaktadır.

Gereç ve Yöntem: 38 yaş üzerindeki KOS/IUI veya IVF tedavisi alan toplam 113 infertil kadin bu retrospektif çalışmaya dahil edilmiştir. Çalışmada KOS/IUI tedavisi uygulanmış 42 hasta, IVF tedavisi uygulanmış 71 hasta bulunmaktadır. İki grup biyokimyasal gebelik, klinik gebelik ve devam eden gebelik sonuçları açısından karşılaştırıldı.

Bulgular: Iki grup arasında biyokimyasal gebelik ve klinik gebelik oranlarl arasında istatistiksel olarak anlaml düzeyde farklılık saptandr. Biyokimyasal gebelik ve klinik gebelik oranları IVF tedavisi alan grupta daha yüksekti $(p 1=0.033, p 2=0.031)$. Devam eden gebelik oranı IVF tedavisi alan grupta daha yüksek olmasina rağmen iki grup arasinda istatistiksel derecede anlamlı bir fark saptanmadı $(p=0.084)$.

Sonuç: Illeri yaş grubundaki hastalarda IVF tedavisi KOS/IUI tedavisinden daha etkin olmast nedeniyle bu yaş grubundaki hastalarda ilk tedavi seçeneği olarak IVF tedavisinin uygulanabileceğini düşünmekteyiz.

Anahtar Kelimeler: in vitro fertilization; intrauterine inseminasyon; ileri yaş

\section{ABSTRACT}

Objective: The aim of the study was to compare the outcomes of patients $>38$ years of age who underwent COH/IUI and those who underwent IVF treatment.

Material and Method: 113 patients who meet the inclusion criteria were enrolled into the study. Of the 113 patients; 42 patients who underwent KOH/IUI and 71 patients who underwent IVF treatment. The biochemical, clinical and ongoing pregnancy rates were compared between two groups.

Results: There were significant differences in terms of biochemical and clinical pregnancy rates between two groups and those were higher in IVF treatment $(p 1=0.033, p 2=0.031)$. Ongoing pregnancy rate was higher in IVF treatment group but there was no significant difference between two groups ( $p=0.084)$.

Conclusion: IVF treatment may be first line treatment option in advanced age women because of the higher success rates of IVF treatment than $\mathrm{COH} / \mathrm{IUI}$ treatment.

Keywords: in vitro fertilization; intrauterine insemination; advanced age
İletişim Bilgileri:

Sorumlu Yazar: Selçuk SELÇUK

Yazışma Adresi: Zeynep Kamil Eğitim ve Araştırma Hastanesi Jinekoloji Bölümü, Üsküdar, İstanbul, Türkiye

E-posta: md_sel@hotmail.com

Makalenin Geliş Tarihi: 27.11.2015

Makalenin Kabul Tarihi: 10.01.2016

DOI: http://dx.doi.org/10.16948/zktb.33976 


\section{GİRIȘ}

Günümüzde eğitim, kariyer planlaması, ekonomik kaygılar gibi değișen sosyokültürel özellikler nedeniyle kadınlarda çocuk sahibi olma yaşı giderek artmaktadır $(1,2)$. Ancak ilerleyen yaşla beraber, kadınlarda fekundite azalmaktadır. Fekunditede azalma 30 yaş üzerinde görülmeye başlar, 35 yaş üzerinde bu oran önemli derecede azalır, 40 yaș üzerinde bu düşüş ciddi şekilde artar ve 45 yaşına doğru yok denecek düzeye inmektedir $(3,4)$. İleri yaşlarda, hem spontan yolla hem de yardımc1 üreme teknikleri ile gebelik elde etme oranı düşmektedir (5-7). Belirtilen yaş grubundaki kadınlarda gebelik elde etme ihtimalini azaltan başlica nedenler; over rezervinin azalması, oositlerde görülen anöploidi oranının artması, tedavi ile elde edilen oosit ve embryo kalitesinin düşmesi olarak belirtilmektedir (8).

Kontrollü ovaryen stimulasyon (KOS) sonrası intrauterin inseminasyon (IUI) ileri yaş grubundaki infertil kadınlarda ilk olarak uygulanan tedavi yöntemi iken invitro fertilizasyon (IVF); IUI başarısızlığ 1 olan olgularda ikincil tedavi yöntemi olarak uygulanmaktadır (9). Bu yaklaşımın ileri yaş grubundaki başarısı çeșitli çalışmalarda araştırılmış ve farklı sonuçlar elde edilmiştir (10).

$\mathrm{Bu}$ çalışmada 38 yaş üzeri infertil kadınlarda KOS/IUI ile IVF tedavilerinin sonuçlarının karşılaştırılması amaçlanmıştır.

\section{GEREÇ ve YÖNTEM}

Zeynep Kamil Eğitim ve Araștırma Hastanesi infertilite bölümünde, KOS/IUI veya IVF veya ICSI tedavisi uygulanmış 38 yaş üzerindeki infertil kadınlar bu retrospektif çalışmaya dahil edilmiştir. 38 yaş üzeri infertil, bazal folikül stimulan hormon (FSH) düzeyleri $<15$ $\mathrm{mIU} / \mathrm{L}$, basal luteinizan hormon, prolaktin ve TSH düzeyleri normal sınırlarda olan, polikistik over sendromu, metabolik ve endokrin hastalığı olmayan, partnerinin sperm parametreleri normal olan hastalar çalıșmaya dahil edilmiștir. IUI tedavisi alan grupta histerosalpingografide (HSG) en az bir tüpün açık olduğu hastlar çalışmaya dahil edilirken, bilateral tubal oklüzyonu olan olgular çalışmaya dahil edilmedi. Gonadotropinle (rekombinant FSH veya human menapozal gonadotropin) ovaryan indüksiyonu 50-100 IU/gün doz aralığında siklusun 2-4. gününde subkütan olarak başland1.

Gonadotropin dozu, antral folikül sayısı, vücut kitle indeksi ve önceki tedaviye yanıt göz önünde bulundurularak belirlendi. Dominant folikül $18 \mathrm{~mm}$ çapa ulaştığında 10.000 IU human koryonik gonadotropin (Pregnyl $\AA$, Organon, Netherlands) veya 250 mcg rekombinant koryonik gonadotropin alfa (Ovitrelle; Merck-Serono, Istanbul, Turkey) subkütan olarak uyguland1. 36 saat sonra IUI işlemi gerçekleştirildi. IVF tedavisinde, agonit uzun protokol veya antagonist protokol kullanıld1. Agonist uzun protokolde, leuprolide asetat (Lucrin ${ }^{\circledR}$, Abbott, France) önceki siklusun 21. Gününde $0.5 \mathrm{mg}$ /gün olarak başland1. Gonadotropin (rekombinant FSH veya human menapozal gonadotropin) yaș, antral folikül sayısı, vücut kitle indeksi ve önceki siklustaki cevaba göre 150-300 IU/gün doz aralığında siklusun üçüncü günü başland1.

Gonadotropin releasing hormon (GnRH) antagonist protokolde, gonadotropinler belirtilen kriterlere göre aynı doz aralığında siklusun ikinci gününde başland1. Önde giden folikülün çapı 14mm'e ulaştığında GnRH antagonist (Cetrotide $\AA$, Serono, Switzerland or Orgalutran ${ }^{\circledR}$, Organon, Netherlands) hCG gününe kadar $0.25 \mathrm{mg} /$ gün dozunda uyguland1. Önde giden folikül $18 \mathrm{~mm}$ çapına ulaştığında 10.000 IU human koryonik gonadotropin (Pregnyl $\AA$, Organon, Netherlands) veya $250 \mathrm{mcg}$ rekombinant koryonik gonadotropin alfa (Ovitrelle; Merck-Serono, Istanbul, Turkey) subkütan olarak uygulandı. 36 saat sonra oosit pick-up işlemi gerçekleştirildi.

IUI işleminden veya embryo transferinden 12 gün sonra serumda beta hCG testi bakıldı. Serum beta hCG seviyesi $>10$ IU olan olgular biyokimyasal gebelik olarak edildi. Pozitif beta hCG testinden üç hafta sonra yapılan ultrasonda intrauterin gestasyonel sac tespit edilmesi klinik gebelik olarak kabul edildi. Gebelik haftasinın 20 haftadan daha uzun sürmesi devam eden gebelik olarak kabul edildi.

\section{Istatistiksel analiz}

Bu çalışmada istatistiksel analiz SPSS 11.5 software programı kullanılarak yapıld1. Grup karşılaştırmalarında Pearson ki-kare testi ve Mann Whithney U testi kullanıldı. Sonuçlar, anlamlılık $\mathrm{p}<0,05$ düzeyinde, $\% 95$ 'lik güven aralığında değerlendirildi. Veriler ortalama $\pm \mathrm{sd}$ veya $\%$ olarak verildi.

\section{BULGULAR}

Çalıșmaya, KOS/IUI tedavisi uygulanmıș 42 hasta ve IVF tedavisi uygulanmış 71 hasta olmak üzere toplam 113 hasta dahil edildi. İki grubun bazal demografik, klinik özellikleri karş1laştırıldı (Tablo 1). 


\begin{tabular}{|c|c|c|c|}
\hline & IUI & IVF & \multirow{3}{*}{$p$} \\
\hline & $(n=42)$ & $(n=71)$ & \\
\hline & ort $\pm s d$ & ort $\pm s d$ & \\
\hline Yaş (yıl) & $40.52 \pm 2.87$ & $40.13 \pm 1.81$ & 0.075 \\
\hline İnfertilite süresi (yıl) & $3.56 \pm 3.12$ & $7.00 \pm 5.89$ & 0.002 \\
\hline Basal FSH (mIU/mL) & $7.56 \pm 2.02$ & $7.98 \pm 2.41$ & 0.378 \\
\hline Basal E2 (pg/ml) & $49.23 \pm 16.26$ & $54.63 \pm 32.06$ & 0.803 \\
\hline Bazal sperm konsantrasyonu (106/ml) & $62.18 \pm 32.59$ & $55.26 \pm 30.59$ & 0.252 \\
\hline Basal total sperm motilitesi (\%) & $59.95 \pm 20.98$ & $65.52 \pm 15.73$ & 0.225 \\
\hline Stimulasyon süresi (gün) & $8.64 \pm 2.97$ & $8.46 \pm 1.98$ & 0.727 \\
\hline Total gonadotropin dozu (IU) & $640.0 \pm 227.99$ & $3105,49 \pm 1133.40$ & 0.000 \\
\hline
\end{tabular}

istatistiksel anlamlılık düzeyi, $\boldsymbol{p}=0.05$ Level (Mann Whitney $\cup$ testi kullanıldI).

\begin{tabular}{|c|c|c|c|}
\hline & IUI & IVF & \multirow{2}{*}{$\mathrm{p}$} \\
\hline & $(n=42)$ & $(n=71)$ & \\
\hline \multicolumn{4}{|l|}{ Biyokimyasal gebelik oranı } \\
\hline$\%$ & 14.3 & 32.4 & 0.033 \\
\hline (n) & (6) & (23) & \\
\hline \multicolumn{4}{|l|}{ Klinik gebelik oranı } \\
\hline$\%$ & 11.9 & 29.6 & 0.031 \\
\hline (n) & (5) & $(21)$ & \\
\hline \multicolumn{4}{|l|}{ Devam eden gebelik oranı } \\
\hline$\%$ & 4.8 & 15.5 & 0.084 \\
\hline (n) & $(2)$ & (11) & \\
\hline
\end{tabular}

Total gonadotropin dozu IVF tedavisi alan grupta KOS/IUI tedavisi alan gruba göre istatistiksel olarak anlamlı düzeyde daha yüksek olarak tespit edildi $(\mathrm{p}<0.001)$. IVF tedavisi alan grupta inferilite süresi istatiksel olarak anlamli derecede daha uzundu $(\mathrm{p}=0.002)$. Yaş, bazal FSH, E2 seviyesi, bazal sperm parametreleri ve stimulasyon süreleri arasında istatistiksel derecede anlamlı bir fark saptanmadı.

KOS/IUI ve IVF tedavisi alan hastalar gebelik sonuçları açısından karşılaştırıldı (Tablo 2). İki grup arasında biyokimyasal gebelik ve klinik gebelik oranları arasında istatistiksel olarak anlamlı düzeyde farklılık saptandı.

Biyokimyasal gebelik ve klinik gebelik oranları IVF tedavisi alan grupta daha yüksekti $(\mathrm{p} 1=0.033, \mathrm{p} 2=0.031)$. Devam eden gebelik oranı IVF tedavisi alan grupta daha yüksek olmasına rağmen iki grup arasında istatistiksel derecede anlamlı bir fark saptanmadi $(\mathrm{p}=0.084)$.

\section{TARTIŞMA}

Bu çalışmada 38 yaş üstü infertil hastalarda IVF tedavisi ile elde edilen biyokimyasal gebelik, klinik gebelik ve devam eden gebelik oranları sirasıly $\% 32,4 ; \% 29,6 ; \% 15,5$ olarak saptanırken KOS/IUI tedavisi ile bu oranlar s1rasiyla $\% 14,3 ; \% 11,9 ; \% 4,8$ olarak saptand1.
$\mathrm{Bu}$ yaş grubunda IVF tedavisi ile elde edilen biyokimyasal ve klinik gebelik oranlar1 KOS/IUI tedavisine göre istatistiksel olarak daha yüksek saptandı. Çalışmamızın sonuçları değerlendirildiğinde, açıklanamayan infertilitesi olan 38 yaş üstü kadınlarda infertilite tedavisinde IVF tedavisinin daha etkin olduğu görülmektedir.

$\mathrm{Bu}$ yaş grubunda over rezervi ve fekundite hızla azaldığı için en etkin ve hızlı infertilite tedavisini uygulamanın önemi diğer yaş gruplarına göre daha da artmaktadır. İleri yaşla beraber oosit sayısı ve kalitesinin azalması, foliküler mikroçevredeki granüloza hücrelerinin ve kanlanmanın olumsuz etkilenmesi ortaya çıkan infertilinin ana sebepleri olarak belirtilmektedir $(11,12)$.

Literaturde ileri yaş infertil kadınlarda optimal tedavinin belirlenmesi amaciyla yapılmış çalışmalar bulunmaktadır. Harris ve ark. tarafindan yapilan, IUI tedavisi uygulanan 130 hastanın dahil edildiği çalışmada, hastalar 38-39 yaş ve 40 yaş üstü olmak üzere iki gruba ayrılmıştır. Canlı doğum oranı 38-39 yaş aralığındaki grupta siklus başına \%6.1, 40 yaş üstü grupta \%2 olarak saptanmıştır. Sonuç olarak, IUI tedavisinin etkinliğinin ilerleyen yaşla beraber azaldığı ancak 38-39 yaş aralığında iki IUI siklusu denenebileceği, 40 yaş üstünde ise 
bir siklustan sonra hastaların IVF tedavisine yönlendirilmelerinin mantıklı bir yaklaşım olacağı belirtilmiștir (9). Farklı bir çalışmada KOS/ IUI tedavisi ile elde edilen canlı doğum oranı hasta başına \%3.9, siklus başına \%1.4 olarak tespit edilmiștir (13). Wiser ve ark. tarafindan retrospektif olarak, açıklanamayan infertilitesi olan $\geq 40$ yaş olgularda ovaryan stimulasyon sonrasi IUI tedavisi ile IVF tedavisi sonras1 elde edilen gebelik oranları karşılaştırılmıștır. KOS/IUI ve IVF tedavisi sonrası klinik gebelik oranları sirasıyla $\% 2.6$ ve $\% 16.9$; canlı doğum oranı ise $\% 2.6$ ve $\% 13.9$ olarak saptanmıștır. IVF tedavisinin bu yaş grubunda en etkili tedavi yöntemi olduğu belirtilmiştir (14).

Bizim çalıșmamızda KOS/IUI tedavisinde siklus başına devam eden gebelik oranları $\% 4.8$ olarak bulunmuștur, bu oranın literatürde belirtilen oranlara göre bir miktar yüksek saptanmasının sebebi çalışmaya dahil edilen hastaların yaș ortalamasının göreceli olarak daha düşük olmasından kaynaklandığını düşünmekteyiz. Human Fertilisation and Embryology Authority (HFEA); 38-39 yaş aralığında IVF tedavisi sonrası canlı doğum oranını siklus başına \%19.2, 40-42 yaş aralığında bu oranı \%12.7, 43-44 yaş aralı̆̆ında \%5.1, 45 yaş üzeri olgularda ise \%1.5 olarak rapor etmiştir (15).

Tsaifir ve ark tarafından yapılan çalıșmada, 40-46 yaş aralığındaki kadınlarda IVF tedavisi ile elde edilen gebelik ve doğum oranları araştırılmış; bu oranlar ilk siklus için sırasıyla \%7.4 ve $\% 4$ olarak saptanmıştır. 40 yaşındaki kadınlarda gebelik oranı ve doğum oranı $\% 13.9$ ve $\% 9.1$ iken 45 yaşında ise $\% 2.8$ ve $\% 0.7$ olduğu ve oranlarda ciddi bir düşüş olduğu belirtilmiştir (Tsaifir 2007). Bizim çalıșmamızda 38-40 yaş aralığında devam eden gebelik oranı \%19.4 iken; 40 yaş üstünde bu oran \%12.5 idi. IVF tedavisi sonrasi elde edilen gebelik oranlarının ilerleyen yaşla beraber azaldığı görülmektedir.

Sonuç olarak; ileri yaș grubundaki hastalarda IVF tedavisi KOS/IUI tedavisinden daha etkin olması nedeniyle bu yaş grubundaki hastalarda ilk tedavi seçeneği olarak IVF tedavisinin uygulanabileceğini düşünmekteyiz.

\section{KA Y N A KL A R}

1. Botting B, Dunnell K. Trends in fertility and contraception in the last quarter of the 20th century. Popul Trends. 2010;100:32-9.

2. Bewley S, Davies M, Braude P. Which career first? BMJ. 2005;331:588-9.
3. Menken J, Trussell J, Larsen U. Age and infertility. Science. 1986;233:1389-94.

4. ESHRE Capri Workshop Group. Fertility and ageing. Hum Reprod Updat. 2005;11:261-76.

5. Devroey, P., Godoy, H., Smitz, J., Camus, M., Tournaye, H., Derde, M.P., Van Steirteghem, A., 1996. Female age predicts embryonic implantation after ICSI: a case-controlled study. Hum. Reprod.11, 1324-1327.

6. Hull, M.G., Fleming, C.F., Hughes, A.O., McDermott, A., 1996. The age-related decline in female fecundity: a quantitative controlled study of implanting capacity and survival of individual embryos after in-vitro fertilization. Fertil. Steril. 65, 783-790.

7. Marcus, S.F., Brinsden, P.R., 1996. In-vitro fertilization and embryo transfer in women aged 40 years and over. Hum. Reprod. Update 2, 459-468.

8. Magarelli C, Pearlstone C, Buyalos R. Discrimination between chronological and ovarian age in infertile women aged 35 years and older: predicting pregnancy using basal follicle stimulating hormone, age and number of ovulation induction/intra-uterine insemination cycles. Hum Reprod. 1996;11(6):1214-9.

9. Harris, I.D., Missmer, S.A., Hornstein, M.D., 2010. Poor success of gonadotropin-induced controlled ovarian hyperstimulation and intrauterine insemination for older women. Fertil. Steril. 94, 144-148.

10. Corsan G, Trias A, Trout S, Kemmann E. Ovulation induction combined with intrauterine insemination in women 40 years of age and older: is it worthwhile? Hum Reprod 1996;11:1109-12.

11. Tsafrir, A., Simon, A., Margalioth, E.J., Laufer, N., 2009. What should be the first-line treatment for unexplained infertility in women over 40 years of age-ovulation induction and IUI, or IVF? Reprod. Biomed. Online 19, 4334.

12. Tatone, C., Amicarelli, F., Carbone, M.C., Monteleone, P., Caserta, D., Marci, R., Artini, P.G., Piomboni, P., Focarelli, R., 2008. Cellular and molecular aspects of ovarian follicle ageing. Hum. Reprod. Update 14, 131-142.

13. Frederick, J.L., Denker, M.S., Rojas, A., Horta, I., Stone, S.C., Asch, R.H., Balmaceda, J.P., 1994. Is there a role for ovarian stimulation and intra-uterine insemination after age 40? Hum. Reprod. 9, 2284-2286.

14. Wiser A et al. Ovarian stimulation and intrauterine insemination in women aged 40 years or more. Reprod BioMed Online. 2012;24:170-3.

15. Human Fertilisation and Embryology Authority (HFEA). Fertility treatment in 2010: trends and figures. London: HFEA; 2010.

16. Tsafrir A, Simon A, Revel A, Reubinoff B, Lewin A, Laufer N. Retrospective analysis of 1217 IVF cycles in women aged 40 years and older. Reprod Biomed Online. 2007 Mar; 14(3):348-55. 